\title{
MODELS OF IMPLEMENTING INNOVATIVE TECHNOLOGIES INTO INDUSTRY
}

\author{
Marzena Walasik ${ }^{1}$, Beata Poteralska ${ }^{2}$ \\ Łukasiewicz Research Network - Institute for Sustainable Technologies, \\ ul. K. Pulaskiego 6/10, Radom, Poland \\ E-mails: ${ }^{1}$ marzena.walasik@itee.radom.pl (corresponding author); ${ }^{2}$ beata.poteralska@itee.radom.pl
}

Received 07 April 2020; accepted 04 May 2020

\begin{abstract}
The paper is aimed at identifying the state-of-the-art in the field of traditional and innovative management of a new product (the result of R\&D works). Against this background, key elements of the management process of new product development (NPD) at R\&D organisations, are identified. The main components of the management process comprise the developed implementation models and dedicated marketing tools, with taking into account the specific character of an R\&D organisation, whose activities should be focused on the commercialisation of obtained research results.
\end{abstract}

Keywords: new product development (NPD), R\&D organisation, dissemination, commercialisation, marketing tools.

JEL Classification: 032, M31.

\section{Introduction}

Over the last few decades, there have been many studies that compared the success and failure of a newly developed product in order to find key success factors (Ernst, 2002). These works relate to the NPD process in market entities focused on profit and the struggle to stay on a highly competitive market (Thomas, 1995; Smith \& Reinertsen, 1998; Boone, 2008). However, managing the development of a new product is also a key aspect of the development activity of R\&D organisations (Lobejko \& Sosnowska, 2013) that nowadays are seen as typical business entities, which should act as innovators by creating and then implementing $R \& D$ results into the economy on a market basis. Creating new, innovative, highly specialised, often individual or short series products and services (results of R\&D works) is the first stage of the process, whose final effect should be commercialization. The literature on the subject does not define how the NPD process should proceed in an $R \& D$ organization, what to do to make scientists better understand what the organizational and market conditions of implementing innovations in the economy are, what factors determine the success of the NPD process referring to the result of R\&D works. The authors of the paper notice a research gap in this regard. Thus, the aim of the article is, based on in-depth literature studies and on the basis of the authors' own commercialization experience in the field of implementing R\&D solutions into business practice, to develop an NPD process dedicated to an $\mathrm{R} \& \mathrm{D}$ organisation. The pro- posed NPD process consists of four stages: (1) generating an idea and developing an R\&D solution, (2) using an appropriate implementation model, (3) choosing and implementing marketing activities, (4) carrying out activities strengthening the market position of an R\&D organisation. Among them, the following ones are considered of key importance: implementation models dedicated to the results of R\&D works and recommended dissemination activities matched to these models, which should be applied depending on the selected model, taking into account the three attributes of emerging solutions, i.e. a type of solution, its character and a commercialization mechanism suggested.

The structure of the paper is as follows; literature review on factors affecting NPD success; original NPD process adapted to the results of $R \& D$ works, discussion of 4 stages of the NPD process for an R\&D organisation, with particular focus on 6 implementation models and the method of model selection. The method depends on the input parameters of R\&D solutions and marketing activities integrated with the dedicated implementation model, the application of such approach supports the transfer of innovations to business practice. The final section concludes the paper and suggests directions for future research based on key findings.

\section{Key success factors of NPD}

The subject of shaping new products has been of interest to researchers since the late 1960s to the 
present. NPD is understood as a series of activities which commences with recognizing an opportunity on the market. The authors of the paper define NPD as a process aimed at developing a new R\&D result and conducting marketing (dissemination) activities, which are focused on the implementation of a new $R \& D$ result into a market economy.

There is a variety of NPD process models in literature (e.g., Tzokas et al., 2004; Crawford \& Di Benedetto, 2002; Peters et al., 1999; Cooper \& Kleinschmidt, 1987b). The models indicate a set of development stages that organisations should follow to carry out the multidisciplinary NPD process.

As early as 1968, the results of a best practice study published in the United States by a consulting company Booz, Allen, and Hamilton (1982) were published. The seven stages of the BAH model comprise: new product strategy, idea generation, screening and assessment, business analysis, development, testing and commercialization. Loch and Kavadias (2008) state that the NPD process consists in generating opportunities, screening and transforming them into activities presented to customers. The NPD process usually comprises the stages of ideas generation, investigation, design, production, packaging and launch on the market (Miguel, 2008). Crawford and Di Benedetto (2002) indicate five phases of the NPD process: opportunity identification and selection, product conceptualisation, screening, pre-technical evaluation and launch.

Because New Product Development NPD is increasingly valued as a key aspect contributing to a success of business's operations, thus, as a result, there has been observed a noticeable increase in the number of studies and analyses aimed at identifying the drivers of new product success. There are numerous factors which influence the success of the process of developing a new or improving an existing product and launching it on the market. Key factors of NPD are indicated: technology (added value of technology, cost reduction thanks to the technology application), marketing (meeting customer needs, production time, profit, market share), management and commercialization process, the process of introducing a new product to the market (profits, possible additional investments concerning the product commercialisation) (Cooper, 1990; Mu et al., 2007; Cooper, 1997).

The commonly mentioned pre-requisite for new product success stressed in the analyses on winners and losers in new product development is customer orientation (e.g. Cooper \& Kleinschmidt, 1987a, 1990; Griffin \& Hauser, 1993; Narver \&
Slater, 1990). NPD success on the high-tech market depends on meeting the consumers' needs. The target consumer should be carefully defined and their needs must be satisfied with a new product idea (Easingwood \& Koustelos, 2000). Furthermore, for the success of a new product on the market, it is necessary that the product not only meets the consumers' expectations, but also provides higher utility than the price paid. To achieve this goal, it is crucial to find out what consumers value most. The ability to identify the consumers' value is a key element of a new product marketing (Krasnikov \& Jayachandran, 2008).

\section{NDP and key success factors in research and development units}

In the literature on product management, little attention has been paid to identifying the stages of NPD and key success factors with reference to particular sectors, including the science sector. For this reason, based on the literature analysis, own experience in the implementation of $R \& D$ results into the economy, taking into account the specific conditions of the functioning of $R \& D$ organizations, the stages of NPD in this type of organizations are proposed, as follows:

- Generating an idea and developing an $\mathrm{R} \& \mathrm{D}$ solution corresponding to the market demand,

- The use of an appropriate implementation model depending on the result of $R \& D$ works,

- Selection and implementation of marketing activities depending on the rules of competing in a particular market, including target segments,

- Carrying out activities strengthening the market position of the R\&D organization as an entity creating a new product.

The expected effect of conducting the indicated stages of the NPD process is commercialization of solutions created in $R \& D$ organizations.

The first stage in the NPD process is to generate an idea and develop a product for which the probability of successful implementation increases in the situation when an innovation is not created according to the model of "technology push" or "science push", but the reverse phenomenon occurs, i.e. R\&D works are influenced by a demand from the market ("market pull").

The second aspect of NPD at an R\&D organization is the adjustment of the implementation model to the rules of functioning on the market and market segments approached. The implementation 
model selected by the R\&D organization significantly affects the effectiveness of the marketization process of generated products, and above all allows achieving satisfactory economic indicators (including financial ones, such as NPV).

The third important issue in NPD is adjusting marketing activities for a new product to the rules of competing on a particular market, which in the modern economy constitute one of the basic premises for the functioning of each economic entity and determine its competitive position. An important element at this stage is the development and segmentation of the market, which thanks to specifying homogeneous groups will determine the needs and requirements of potential buyers.

While implementing the last stage of the NPD, which is conducting activities strengthening the market position of an R\&D organization, it is advisable to undertake both: image-building activities that are primarily aimed at strengthening the brand of an R\&D organization on the national and international arena, as well as undertaking activities within individual marketing.

No less important element in this last stage of implementing NPD in an R\&D organization is monitoring of the level of customer satisfaction with the new product. It is also important to inform clients about undertaking work on creating new generations of a particular type of products or services.

\subsection{Generating and developing a product corresponding to market demand}

At the first stage of the NPD process, it seems that the chacteristic features of an $R \& D$ organization play a key role because by definition such entities are to be a carrier of innovations.

The product portfolio of $R \& D$ organizations comprises products, technologies and services that should be a carrier of innovations.

Michael E. Porter (1980) states that innovation includes technological improvements, better methods, and ways to do things. This is evident in product and process changes, new marketing approaches, and new forms of distribution. Innovation is a new, original solution that is the result of the cognitive process, the process of increasing knowledge resources, which finds practical application. Thanks to these processes and new ways of using resources, the existing or new needs of customers are better satisfied. Innovations have different characteristics. First of all, they are associated with uncertainty concerning the results of their activities. R\&D organizations should have capabilities enabling to assess them as innovative entities
(Sosnowska et al., 2000). It means that among others they have a team of creators, innovators guaranteeing a high innovatineness level of the developed $R \& D$ results, have the ability to permanently generate innovations, the ability to shape the future (foresight).

The identification of ideas comprising potential far-reaching research and application areas and the directions of their development is of key importance. Actions aimed at generating ideas can be carried out with the use of the approaches including classical planning, taking into account the direct demand of economy, and the subject of cooperation with other $R \& D$ organizations or with the use of future studies methods, with a particular reference to foresight. The authors of this article use foresight as a key tool for generating future technologies and products, while incorporating subjects of research inspired by other sources, for example, cooperation with business and science. The choice of foresight from among other approaches used in future studies, including forecasting, predicting, and planning, stems from the fact that foresight is used not only to assist in the preparation and decision making in the present concerning the future, but it primarily supports active shaping of the future (Cuhls, 2003). Foresight methods help identify the emerging development trends and weak signals, and they also study the potential for their further development and future importance.

What is very important at this stage, and what is lacking for $R \& D$ organizations, is flexibility in adapting to changing operating conditions, constant communication with market entities, in order to effectively learn their current and future needs, the ability to use the company's innovative capabilities of an R\&D organizations to maintain a highly competitive position, built on key competencies of scientists. To this end, it is necessary to implement three subsequent elements of the NPD process in an $R \& D$ organization described in the further part of the paper.

\subsection{Implementation models}

On the basis of the literature review on business models dedicated for market entities, a set of implementation models has been defined, to be applied by a marketing-oriented $R \& D$ organization. These modelas are one of the key elements of the new product management process in such entities.

As part of the marketing-oriented R\&D organization, a set of 6 models of implementing innovative technologies into industry have been defined. These are: The Innovation Model, The Niche 
Model, The Sub-supply Model, The Comprehensive Model, The Market Model and The Infrastructure / Customization Model. The interpretation of these six hybrid models created is as follows:

M1 - The Innovation Model - is based on gaining and keeping technological advantage It is achieved thanks to regular observations of the external environment, intensive research and development works, orientation on innovation, creation of innovative products that would meet the clients' needs. Innovations should be turned into specific usability for recipients. The model is applicable when the scientific results are transformed into a specific product or service that generates revenue.

M2 - The Niche Model - recommended when the ongoing $\mathrm{R} \& \mathrm{D}$ works are resulted in new ways of implementing processes, solving important social and environmental problems. It is often based on conducting research for enterprises as part of outsourcing, which guarantees long-term cooperation. It is useful in case of expanding sectors, in which niches extist and it is needed to keep up with the growing demand.

M3 - The Sub-supply Model - focuses on configuring the offer meeting the unique needs of the recipient, presenting to a specific customer a product or service prepared especially for him. The model is recommended for the use in case of complex products that require close cooperation with customers. The model assumes not only building close and long-lasting two-way relations, but also cooperation with the recipient in creating and implementing the offer.

M4 - The Comprehensive Model - designed for comprehensive products, processes or technologies, dedicated to solutions consisting of many interrelated elements, accompanied by various additional services, offered not only at the time of the purchase, but also later during operation. It promotes concentration on gaining customer loyalty, high quality of service and individualisation.

M5 - The Market Model - used when the effects of R\&D works are focused on solving social, civilization and environmental problems. This is served by observing market trends that the public is focused on. The informational message should emphasize the way in which a given solution can contribute to solving the above-mentioned types of problems that are relevant to the society at a given moment.

M6 - The Infrastructure / Customization Model - is based on creating and providing complete technology along with new technological capabilities which allow launching new ventures ensuring mass access for potential recipients. The model ensures standardization of previously personalized services and offering them at a lower cost.

Given the purpose of the hybrid models, namely, their practical use in the process of innovation transfer to economic practice, each of the six models has been verified for applicability dependent on the following three key attributes (input parameters) of $R \& D$ results: (1) the type of solution (product) (Mazurkiewicz et al., 2015): services (e.g., IT, surface engineering), materials (e.g., chemical, textile, composites), systems (e.g., software, computer systems), technologies (e.g., chemical, mechatronic) and equipment (e.g., test and research apparatus); (2) the scale of production: the production of a single unit, the small series production of units or sevices, or the large series production; (3) Mechanism of commercialization: Sale, Licence, Service, or Spin off.

The work proceeded to indicate forces of dependence between the hybrid models and the input parameters. Matrices of dependences were built for each combination of a solution type (5 possibilities), the scale of the production (3 possibilities), and the mechanism of commercialization (4 possibilities) and their analysis conditioned the selection of adequate models.

Each model is assumed to be a conditional path for each particular combination of input conditions (variable categories). Results of the analysis suggested which model should be applied, depending on input parameters.

\subsection{Dissemination system and marketing tools dedicated to implementation models}

Support for the NPD process, at the stage of adjusting marketing activities to the rules and principles of competing on a given market, is provided by properly selected marketing tools, creating the possibility of implementing the results of $R \& D$ works into the economy through a more effective dissemination process. A system for the dissemination of innovative solutions created at an R\&D organization has been developed, consisting of 5 main stages: analyzing the market situation, segmentation process, creating distinctive features of the solution, developing a dissemination strategy, organizing dissemination activities.

The first stage of dissemination activities market situation analysis includes an industry (supply analysis) study in which an R\&D organization will operate offering the product, customers to whom the solution will be addressed (demand analysis) and suppliers of components and their proposed commercial conditions. 
The second stage - a summary of the market situation analysis and - at the same time the main goal, which is to choose the most promising segment of the market through the so-called segmentation. To this selected part - the so-called target market is then directed the product offer of an R\&D organization. There are numerous segmentation criteria in the literature (Kotler, 2012; Garbarski, 2011). Due to the specificity of products developed in $R \& D$ organizations, demographic criteria (e.g. industry, size of the enterprise) and situational criteria (e.g. specialized applications, extended scope of functionality) have been recognized as key ones.

The choice of the target market, requiring knowledge of the needs and requirements of consumers as well as the strengths and weaknesses of potential competitors, allows to take the next step, which is to create distinguishing features of the solution, thereby identifying a market niche, i.e. identifying an area not yet satisfied by other suppliers. The factor that influences customer purchasing decisions can be both price and quality, the functionality of a given product or service. Finding a market niche is usually associated with a significant increase in the chances of the successful launch of a product or service on the market, i.e. the success of the venture. According to the definition of market niche, an R\&D organization should compete primarily on the basis of diversity (specialized solutions) - the most important attribute is the functional properties of the products or services offered.

Developing a dissemination strategy (the fourth stage ) is a procedure for planning dissemination activities that involves designing product promotion in such a way that a selected market segment will see its attractiveness and uniqueness. The ability to indicate these features allows the product to be distinguished from its substitutes.

When preparing a product presentation for dissemination purposes, its main advantages should be indicated. Evidence to support product effectiveness should be provided both in numerical form (economic viability analysis) and by representatives of target groups involved in the implementation of the solution who will credibly certify its market potential and functionality.

It is important to determine, on the basis of the results of the market segmentation, who are the recipients of dissemination activities (selection of key recipients), what message will be communicated, what form of communication will be chosem by indicating the dissemination tools used for communication.
The dissemination strategy should be thought out during the product concept phase. Other tools will be appropriate at the initial stages of implementing the innovations and other tools when the product is ready for production.

In the case of services two different market niches - e.g. a potential recipient of a solution expecting the lowest prices, the second, for whom it is primarily important to meet the needs even at a higher price - creating a special - sophisticated technological offer that satisfies certain benefits:

- Meeting the unusual expectations of customers requires the use of a highly individualized composition of instruments of competition (including product and dissemination tools).

- Acquiring and maintaining a competitive advantage by offering ways to solve problems (effectiveness in meeting clients' needs) based on innovative activities in the area of: products (completely new or modified products, improvement of the type / manner of providing services), process (new or significantly improved production methods, significant changes in the field of machines, technologies, e.g. automation of manufacturing processes), less often organizational (new methods of organization of activities and procedures) or marketing (making changes in designs, product appearance).

- Offering various additional services (e.g. extended period of free service).

The next stage, after developing a strategy, is to organize dissemination activities involving the implementation of marketing plans, taking into account available human and financial resources.

One of important factors conditioning effective dissemination of innovations is matching the proper marketing tool to the right model. The analysis focused on the choice of dissemination tools depending on the model used indicates that these tools should be differentiated.

For M1 - the Innovation Model, it is particularly recommended to present the benefits of the product core, disseminate information on innovations through scientific publications and using online tools such as newsletter and e-mailing. These tools help strengthen the message directed to the environment and build the desired image of the institution as a creator of innovations. Price competition is not recommended for innovative products. At the initial stage, direct distribution is recommended, then intermediaries with proven innovation diffusion channels can be used. 
For M2 - the Niche Model - often used to provide services to external entities, the most useful marketing tool is promotion, including instruments that affect the building of customer confidence. Presenting the benefits of the product core is suggested. Direct sales are the dominant form of sales. The proactive attitude of the staff plays a big role, meaning care for satisfying the needs of the buyer by implementing the service process with the highest quality standards. It is also recommended to keep the website up to date.

For M3 - the Specialized Model - it is recommended to clearly present the benefits of the product. It is necessary to indicate not only the product core (the main benefit obtained by the customer) but also the extended product, covering the latest technical achievements, delivery and installation conditions, maintenance and advice. Because the product is atypical and unique, it is important to maintain direct contacts with contractors. Contractors may be interested in the offer obtained at specialist fairs. Due to the uniqueness of the product, a wide promotional media message is not needed. It seems that traditional printed materials can be a good tool for creating awareness among potential recipients of the existence of a subsupplier and its offer. Similarly to the niche model, distribution should be direct.

For M4 - the Comprehensive Model - a particularly important marketing tool is to present an expanded scope and package of benefits from product implementation. Complex products are easier to present "live", hence the role of fairs and exhibitions in this model should be emphasised. An important promotional tool is placing information about the solution in industry portals. It is important to recognize the needs of contractors and the volume of demand. For solutions offered on a larger scale, it is worth transmitting messages to the media (e.g. sponsored articles in the professional press), printed promotional materials and those in the electronic form posted on the website should be considered. Price is not a key competitive tool. Other considerations include functionality, technical support, image and experience of the supplier, user reviews. Direct distribution channels are recommended for smaller-scale operations, in case of more users it is worth considering the involvement of intermediaries.

For M5 - the Market Model - as in other models (e.g. Comprehensive Model), the usability and benefits of the product should be promoted, with particular emphasis on its social or environmental functions. The product's qualities should be promoted by participating in fairs and exhibitions, and an intensive message should be provided, indicating the role of the product for the society and the economy. It seems that publications on the results of research on the product and the effects obtained thanks to it, with particular emphasis on positive social or environmental impacts, can bring a good effect. Traditional printed and electronic (www) forms of promotion are recommended. A competitive price is one of those assets that can significantly accelerate the diffusion of a new solution into the economy. The choice of the distribution method depends on the scale of demand.

For M6 - the Infrastructure / Customization Model - promoting for sublime clients - in the first place, partners from the value chain (suppliers or recipients) are provided with information showing the $R \& D$ result's organizational capabilities (the physical and material, financial, human resource, and the information and management capabilities) (Poteralska \& Mazurkiewicz, 2019). In addition, promoting the value of the enterprise by participating in fairs and joint venture meetings should be taken into consideration. Price is not a key competitive tool. Other considerations comprise technical support, image and experience of the supplier or the amount of revenue expected to be generated. It is worth considering the involvement of a professional broker who knows the industry.

The outlined elements that make up the dissemination system in an $R \& D$ organization reflect the dimensions of the marketing perspective as a space for NPD activities resulting in commercialization and the results of $R \& D$ works.

\subsection{Actions strengthening the market position of an R\&D organization}

The last stage in NPD carried out at an R\&D organization is conducting activities strengthening the market position of the entity implementing the new product. It is necessary to plan to carry out two-way information and promotion activities: on the one hand, taking into account horizontal activities including the dissemination of information about an $R \& D$ organization, which include the promotion of new products at national and international conferences and symposia and by publishing scientific articles in the open- access.

On the other hand, the promotion of the specific effect of the implementation of $R \& D$ works is taken into account. From the point of view of starting dissemination activities, it is necessary on the basis of data collected as a result of market analysis and segmentation process, to prepare product information (what innovative solution has been/will be developed; for what purpose it has 
been created and what needs it meets; what is the scope of functionality; the quality level of the solution; how it differs from solutions developed by competitors; in what respect is it better; how can the solution be used on a larger scale by other entities; what is the impact of the solution's application on the environment or the society; what are the economic benefits of using the solution).

The follow-up phase (occurs when the commercialization process is successful), is the next stage, which is a very important aspect of shaping partner relations with clients and building a positive image of an $R \& D$ organization on the market.

To gain and maintain a strong market position actions related to handling complaints or repairing and replacing a product should be taken. In modern companies, there are special after-sales service programs so that the customer with the acquired product is not left alone. One of the tools used in the follow-up phase by R\&D organizations can be a centralized database of contractors. It provides a rapid flow of information on the subject and the issues signaled by the client, including those in the field of improving the functionality of the product. An important element of after-sales service is fast, efficient and professional service that will ensure product repair or replacement. In our NPD process, a pro-client $R \& D$ organization should contact the customer at least several times a year, including e.g. when it is launching a new product generation, when the review time is approaching, e.g. installation service, the license agreement expires, on the occasion of the holidays/jubilee, etc. The CRM system is irreplaceable here, i.e. customer relationship management, where it is necessary to collect information, e.g. on the purchase history of a given customer, their preferences, expectations, or even the date of birth.

\section{Conclusions}

In the era of dynamic market changes, growing competition between entities, increasing requirements and changing tastes of customers, the process of creating and developing new products is an indispensable activity for both companies and $\mathrm{R} \& \mathrm{D}$ organizations. These issues are widely analyzed in relation to enterprises, however in relation to $\mathrm{R} \& \mathrm{D}$ organizations they are understudied. It is necessary for $R \& D$ organizations to subordinate their activities in the area of NPD to the needs and requirements of customers, because they are the foundation of business, which provides them a place in a competitive market of innovations.
The article identifies key elements (stages) of the management process of a new product development (NPD) in R\&D organizations.

R\&D organizations can significantly control the process of new product development and have a fundamental impact on the level of success of the implemented process. Based on the analyses carried out, it can be concluded that the success of the NPD implementation is determined by a large number of factors on which the R\&D organization can have an impact. New product development (NPD) is a path, not a destination; a path that R\&D organizations, more than ever, should follow to survive in the present unpredictable and dynamic market.

The article focuses on the key, according to the authors, stages of the NPD process: creating implementation models and a system for disseminating innovative solutions. Since various attempts to effectively link research and development, implementation and business works related to the application of research results in business practice are observed, it is considered advisable to create a basis in the practice of $R \& D$ organizations for further verification of the proposed NPD cycle, verification and maybe creation of further implementation models implanted in R\&D organizations as well as creating sets of dissemination and marketing activities dedicated to these models, which in the first stage build, in the next stage strengthen the market and competitive position of $R \& D$ organizations, as entities not only creating but above all implementing innovative products in market practice affect the level of economic development.

\section{References}

Boone, J. (2008). Competition: Theoretical parameterizations and empirical measures. Journal of Institutional and Theoretical Economics, 164(4), 587611. https://doi.org/10.1628/093245608786534640

Booz, Allen, \& Hamilton. (1982). New products management for the 1980s. New York.

Cooper, R. G., \& Kleinschmidt, E. J. (1987a). New products: what separates winners from losers? Journal of Product Innovation Management, 4(3), 169-184. https://doi.org/10.1111/1540-5885.430169

Cooper, R. G., \& Kleinschmidt, E. J. (1987b). Success factors in product innovation. Industrial Marketing Management, 16(3), 215-223. https://doi.org/10.1016/0019-8501(87)90029-0

Cooper, R. G., \& Kleinschmidt, E. J. (1990). New products: The key factors in success. American Marketing Association, Chicago, IL. 
Cooper, R. G. (1990). Stage-gate systems - A new tool for managing new products. Business Horizons 33(3), 44-54. https://doi.org/10.1016/0007-6813(90)90040-I

Cooper, R. G. (1997). The dimensions of industrial new product success and failure. Journal of Marketing 43(3), 93-103. https://doi.org/10.1177/002224297904300310

Crawford, C. M., \& Di Benedetto, C. A. (2002). New products management. McGraw-Hill/ Irwin.

Cuhls, K. (2003). From forecasting to foresight processes - new participative foresight activities in Germany. Journal of Forecasting, 2(2), 93-111. https://doi.org/10.1002/for.848

Easingwood, C., \& Koustelos, A. (2000). Marketing high technology: preparation, targeting, positioning and execution. Business Horizons, 43(3), 2734. https://doi.org/10.1016/S0007-6813(00)89198-3

Ernst, H. (2002). Success factors of new product development: A review of the empirical literature. International Journal of Management Reviews, 4, 140. https://doi.org/10.1111/1468-2370.00075

Garbarski, L. (Ed.) (2011). Marketing. Koncepcja skutecznych działań. Polskie Wydawnictwo Ekonomiczne.

Griffin, A., \& Hauser, J. R. (1993). The voice of the customer. Marketing Science, 12(3), 1-27. https://doi.org/10.1287/mksc.12.1.1

Kotler, P. (2012). Marketing. Rebis.

Krasnikov, A., \& Jayachandran, S. (2008). The relative impact of marketing, research-and-development, and operations capabilities on firm performance. Journal of Marketing, 72, 1-11. https://doi.org/10.1509/jmkg.72.4.1

Loch, C. H., \& Kavadias, S. (2008). Handbook of new product development management. Routledge. https://doi.org/10.4324/9780080554402

Łobejko, S., \& Sosnowska, A. (Ed.). (2013). Komercjlaizacja wyników badań naukowych. MSODI, Warszawa.

Mazurkiewicz, A., Belina, B., Poteralska, B., Giesko, T., \& Karsznia, W. (2015). Universal methodology for the innovative technologies assessment. In R. P. Dameri \& L. Beltrametti (Eds.), Proceed- ings of the 10th European Conference on Innovation and Entrepreneurship (pp. 458-467). Academic Conferences and Publishing International Limited, Reading.

Miguel, P. A. C. 2008. Portfolio management and new product development implementation: A case study in a manufacturing firm. International Journal of Quality \& Reliability Management, 25, 10 23. https://doi.org/10.1108/02656710810843540

Mu, J., Peng, G., \& Tan, Y. (2007). New product development in Chinese enterprise key successes factors managerial prospective. International Journal of Emerging Marketing, 2(2), 123-143. https://doi.org/10.1108/17468800710739216

Narver, J. C., \& Slater, S. F. (1990). The effect of market orientation on business profitability. Journal of Marketing, 54, 20-35. https://doi.org/10.2307/1251757

Peters, A., Rooney, E., Rogerson, J. H., McQuater, R., Spring, M., \& Dale, B. (1999). New product design and development: A generic model. The TQM Magazine, 11, 172-179. https://doi.org/10.1108/09544789910262743

Porter, M. E. (1980). Competitive strategy. The Free Press.

Poteralska, B., \& Mazurkiewicz, A. (2019). Organisational CAPABILITIES of an R\&D organisation: a key factor of innovation development. In P. Liargovas \& A. Kakouris (Eds.), Proceedings of the 14th European Conference on Innovation and Entrepreneurship (pp. 823-833). Academic Conferences and Publishing International Limited, Reading.

Smith, P. G., \& Reinertsen, D. G. (1998). Developing products in half the time (2 ed.). John Wiley \& Sons, Inc.

Sosnowska, A., Łobejko, S., \& Kłopotek, A. (2000). Zarzadzanie firma innowacyjną. Difin.

Thomas, R. J. (1995). New product success stories: Lessons from leading innovators. John Wiley \& Sons.

Tzokas, N., Hultink, E. J., \& Hart, S. (2004). Navigating the new product development process. Industrial Marketing Management, 33, 619-626. ttps://doi.org/10.1016/j.indmarman.2003.09.004 